\section{Questión}

Periodismo / Comunicación

ISSN 1669-6581

Hacer la nuestra con tranquilidad. Jóvenes, rock, política en la revista Humor durante la última dictadura (1979-1983)

Eduardo Raíces

Question/Cuestión, Nro.67, Vol.2, diciembre 2020

ISSN: 1669-6581

URL de la Revista: https://perio.unlp.edu.ar/ojs/index.php/question/

IICom - FPyCS - UNLP.

DOI: https//doi.org/10.24215/16696581e411

\title{
Hacer la nuestra con tranquilidad
}

Jóvenes, rock, política en la revista Humor durante la última dictadura (1979-1983)

\section{Doing our things easy}

Youth, rock, polítics in Humor magazine during last military dictatorship (1979-1983)

\section{Eduardo Raíces}

Facultad de Ciencias Sociales;

Universidad de Buenos Aires

Argentina

eraices2015@gmail.com

https://orcid.org/0000-0001-6299-0968 


\title{
Resumen
}

El presente artículo aborda las representaciones sobre los y las jóvenes contenidas en la célebre revista Humor durante el periodo de la última dictadura militar (1976-1983). Se estudia el modo en que fue abordado este sujeto colectivo desde su materia humorística primordial pero, asimismo, desde las formas discursivas "serias" del ensayo, la crítica de medios, musical y artística y el análisis político. Para ello, se indaga un corpus compuesto por textos escritos, humor gráfico e ilustración de notas. Los materiales seleccionados para este estudio comprenden el periodo 1979-1983. Las conclusiones subrayan que la revista abrió espacios de participación de los y las jóvenes, incorporó a algunos a su staff y tendió a reflejar en sus páginas un modelo de juventud inconformista y crítica en un contexto de clausura de otros espacios de socialización. Asimismo, que la identidad juvenil en Humor se organizó alrededor del rock, objeto de una sección importante coordinada por una joven colaboradora. Con la crisis de la dictadura, emergería polémicamente el interrogante por el rol juvenil en el futuro escenario democrático, sin que el debate entre jóvenes y adultos "apolíticos" y "comprometidos" encontrara posiciones convergentes.

\section{Palabras clave}

Prensa gráfica; dictadura; Humor; jóvenes

\begin{abstract}
This article deals with representations of Youth in Humor magazine during the period of Military Dictatorship (1976-1983). We study the ways this collective Subject was present in the magazine from its primary humoristic language but,
\end{abstract}


as well, we examine their "serious" discursive forms like Essays, Art and Media Critique and Political Analysis. To do this, we inquired a corpus composed of texts, cartoons and illustrations. The selected materials for this study cover the years 1979-1983. Conclusions highlights that Humor opened spaces of participation for youngsters, brought in some of them and tended to reflect a nonconformist and critical Youth model in a context of closure of other spaces of socialization. Likewise, we demonstrated that juvenile identity in Humor was organized around rock music, the subject of a specific section of relevance, coordinated by a young collaborator. With the crisis of the dictatorship, would emerge polemically the interrogation on Youths role in face of future recovery of democratic regime, but the debate shared between "apolitical" and "compromised" youngsters and adults did not lead to convergent positions.

\section{Keywords}

Press; military dictdorship; Humor; youth

"Quince años de rock nacional siguen en pie como fuerza de cambio. La música argentina canta lo que pasa aquí y ahora, mientras nadie lo canta. $Y$ diez mil personas hacen coro."(1) 


\section{Introducción}

El presente artículo se aplica a considerar las representaciones sobre los y las jóvenes contenidas en la revista Humor durante el periodo de la última dictadura militar (1976-1983). Esta célebre publicación aparecida en 1978 y dirigida por Andres Cascioli ostentó un lugar destacado en la prensa disidente, medido por el notorio ascenso en sus ventas, su repercusión y la incorporación paulatina de firmas destacadas de la prensa, la crítica, el ensayismo y el análisis político, sin haber perdido la connotada base humorística gráfica y escrita de origen (Burkart, 2012; 2017; Raíces, 2019).

Si la "juventud" como categoría social supo cobrar consistencia e inteligibilidad en las décadas precedentes, durante la dictadura sus integrantes fueron puestos bajo sospecha y control, no solo con atención a su asociación a la militancia previa a 1976, sino también a prácticas y consumos culturales que les estaban asociados, como el de la música rock. En esta oportunidad, veremos cómo en Humor fue abordado este sujeto colectivo desde su materia humorística primordial pero, asimismo, desde las formas discursivas "serias" del ensayo, la crítica de medios, musical y artística y el análisis político. Para ello, presentamos un corpus compuesto por textos escritos, humor gráfico e ilustración de notas. A los fines indicados, los materiales seleccionados para este estudio comprenden el periodo 1979-1983. El enfoque empleado es cualitativo y se aplica al análisis de contenidos.

\section{Jóvenes en dictadura}

Un aspecto coincidente en buena parte de la bibliografía sobre la renovación y contestación cultural en la última dictadura, es que en su componente social los y las jóvenes tuvieron un papel prominente (Alabarces, 1993; Pujol, 2007a; 
2007b; Margiolakis, 2016; Benedetti y Graziano, 2007 son los contemplados por nosotros). Distintas expresiones musicales, literarias, de las artes visuales y periodísticas tuvieron jóvenes impulsores decididos, en un contexto de prohibición, restricción o simple inconveniencia de otras prácticas colectivas, con la política en lugar preeminente luego del activismo previo a 1976.

La génesis estructural y el reconocimiento de un segmento social "juvenil" como tal, echaron sus bases en la modernización tecnológica, laboral, mercantil y cultural gestada durante el primer decenio peronista, y se consolidaron con el crecimiento y diferenciación social de las capas medias urbanas en los años 60, bajo el condicionamiento de la "moratoria social" (Margulis y Urresti, 1996, pp. 13-30; Pujol, 2007b). Fue identificado a lo largo de la década con las modificaciones en los modelos y normas de vida, en los hábitos, sexuales, de consumo, en la emergencia de nuevas corrientes artísticas y de la radicalización política (Pujol, 2007b; Manzano, 2010, p. 367). Estas transformaciones también impactaron y se promovieron desde el campo mediático, siendo registradas por los magazines de los 60 -en parte, producto ellos mismos de tales cambios societales- (Manzano, 2010, p. 367). Para 1972 aparece una antecesora fundamental de Humor, la revista Satiricón, nutrida del espíritu contestatario de la década previa. Este medio reflejó en sus páginas desde su lenguaje humorístico y punzante la educación sexual, la ecología, el auge del orientalismo y el activismo político, entre muchos otros temas contemporáneos relacionados con los intereses juveniles (Burkart, 2017).

Como parte esas transformaciones, se contó un fenómeno de intrínseca extracción juvenil en el tránsito de los años 60 a los 70 : el rock. El género, imbuido del ideario contracultural, vehiculizó un vínculo tenso con la industria cultural (Alabarces, 1993, pp. 23 y ss.; Pujol, 2007b, pp. 310-313 y 321-325; 
Benedetti y Graziano, 2007, pp. 17-19; Manzano, 2010, pp. 384-386). Por otra parte, el movimiento rockero guardaba una relación controvertida con otra práctica juvenil generalizada, el activismo político - desde el cual con frecuencia el género era calificado de extranjerizante y distractor de las energías juveniles (Pujol, 2007b, pp. 312-313).

Durante el periodo histórico dictatorial que nos ocupa, se demostró la preponderancia de los y las jóvenes, al menos por la "moratoria vital" del rango etario, entre las víctimas de la desaparición forzada de personas (CONADEP, 1995 [1985], p. 199). (2) La represión hizo foco en las militancias políticas y sindicales, en sus redes de apoyo y simpatizantes. Las prácticas contraculturales como el rock no se erigían contra el orden social -en todo caso, entrañaban en algunos casos propuestas de vida "alternativas" al sistema-, pero se asociaron al consumo de drogas y a conductas disolutas y fueron objeto de vigilancia (Pujol, 2007a, pp. 21-22 y 25; Alabarces, 1993, pp. 80-81). La clausura de la actividad político partidaria y las medidas represivas contra toda forma de oposición o disidencia interrumpieron canales de notoria participación juvenil. Otros se generaron o reconvirtieron en función de las nuevas condiciones, como los recitales de rock. Promediando la década, se volvieron un espacio de reunión pública de congéneres (Alabarces, 1993, pp. 73-4).

\section{Dolina: “¿A quién le ganaron los jóvenes?”}

Alejandro Dolina, colaborador permanente de Humor, describe en "La amenaza del jean" a los jóvenes de su presente con una ironía que no dejaba de dar cuenta de su omnipresencia social. Publicado en uno de los primeros números de Humor, el texto marcaba de entrada su presencia en la agenda temática de 
la revista. Desde su título, el ensayo identificaba a su sujeto con un elemento antonomástico de su vestimenta, la versión local de los jeans estadounidenses o "vaqueros", comercializada desde 1958 -por la época en que comenzaba a difundirse el rock \& roll como género musical (Manzano, 2010, pp. 377-379)-. (3)

La aparente "amenaza" era presentada por Dolina como un viraje hacia una suerte de juvenilizacion social expresada en el comportamiento imitativo en los adultos, en la publicidad y en patrones de consumo que hacían que "muchos de nuestros chicos se parezcan más a un joven de Birmingham que a un pibe de Santos Lugares". El autor asociaba esta alienación cultural con la apertura de mercado. En julio de 1978 se había estrenado en los cines argentinos "Fiebre de sábado por la noche", en la que su protagonista John Travolta, al son de los ritmos disco, encarnaba un prototipo juvenil despreocupado y absorto en el esparcimiento. Este modelo juvenil se acercaba al promovido por la dictadura, en tanto que «la moda disco no era una fuerza liberadora. Por el contrario, refuerza una imagen de juventud satisfecha y divertida. Era la juventud 'blanca' que destacaba el ministro [de educación nacional, Ricardo] Bruera: la que estudiaba sin chistar, juntaba para comprarse el último modelo de pantalones Wrangler y salía a divertirse los sábados a la noche.» (Pujol, 2007a, p. 92). De acuerdo a las taxonomías de la época, se trataba de una juventud, en el lenguaje juvenil de la época, "cheta" (Alabarces, 1993, p. 54). Dolina, en tal sentido, no solo ironizaba sobre las distancias generacionales que lo alejaban, camino a la madurez, de esta juventud, sino que alegaba en defensa de la "consciencia nacional" ante lo que entreveía como su extranjerización ideológica y material. Tanto compartía con algunos colaboradores de Humor una adscripción nacional-popular proclive a esa 
postura, como sintonizaba con los pronunciamientos críticos de la revista respecto a reivindicar la producción nacional frente a la avalancha de importaciones, entre ellas las de la industria cultural metropolitana. (4)

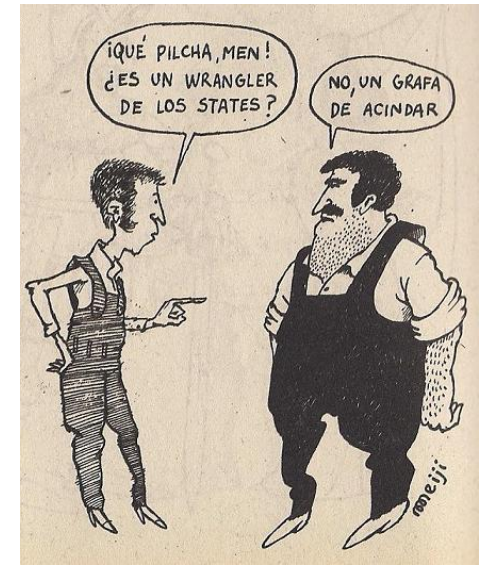

Los jardineros de jean como un elemento ambivalente de distinción de clase.

Chiste de Meiji en Humor.(5)

El dibujante Meiji, en una viñeta anexa al ensayo, complejizaba y enriquecía el argumento doliniano por la vía humorística, al presentar una situación donde se mezclaban condición etaria y situación de clase. Retomaba el elemento de vestimenta jean en su versión "jardinera", para mostrar cosmovisiones en conflicto. El uso por parte del joven de los términos men y states en su pregunta refería a elementos de distinción. El primero, gentilicio de jerga entre los jóvenes de clases medias de la época; el segundo, referencia geográfica de los Estados Unidos. Ambos, empleados por Meiji para denotar el cosmopolitismo del joven, pendiente de las novedades metropolitanas. Precisamente, el giro sobre el que se monta el chiste radicaba en la desorientación del "joven blanco" ante un obrero corpulento y desaliñado, que compartía el uso del "jardinero" pero no como aquel por moda, sino como 
indumentaria laboral. Su estampa recia, personificación del "hombre de pueblo" $y$, como tal, de un estereotipo de la nacionalidad y la respuesta acorde dada al joven, demostraba que entre ellos no había comprensión posible. Situación que, años antes, podría haber tenido otra resolución gráfica bajo la lógica del compromiso político (recuérdese la consigna "Obreros y estudiantes, unidos adelante" y el proceso de peronización de las clases medias).

Lo que para Dolina suponía un corte entre generaciones y consumos de jóvenes de su propio segmento social, en el chiste de Meiji se revelaba como una fractura que añadía a la extranjerización juvenil la división de clases (y, de hecho, el obrero representado es adulto, no joven). Ambas producciones, por otra parte, respondían a una mirada crítica social de actualidad y evitaban comparaciones con las juventudes precedentes, imbuidas de un compromiso que contemplaba lo nacional.

Por la misma época, en la sección de correspondencia, una carta proponía a la entonces responsable de los reportajes de Humor, Alicia Gallotti, que hiciera lo propio con el rockero Charly García. Con ello, disparó un intercambio de opiniones a favor y en contra, sobre el estatus artístico del género y sobre su posible inclusión dentro de una revista humorística. Participaron jóvenes autocaracterizados como tales, junto a adultos que tendieron, de acuerdo a las cartas publicadas, a oponerse a la propuesta. (6) El módico debate fluctuó entre la defensa y la descalificación artística con un tono desenfadado e igualitario, donde ambas partes se "tuteaban" epistolarmente. Este intercambio se expandió luego a una discusión sobre la condición contemporánea de la juventud. Las opiniones se perfilaron entre el cuestionamiento de la descripción de la juventud de Dolina y las solidarias con el articulista. Advertido de las repercusiones de su nota, convocó a través de la revista a una mesa redonda 
para encontrarse con los y las jóvenes que habían escrito a la sección. Al evento asistió un conglomerado juvenil amplio en su franja etaria (de los 15 a los 29 años). El debate transitó los tópicos de la capacidad de raciocinio juvenil y de su "libertad interior" (sic), y de la incomunicación entre la generación juvenil y la de sus padres como consecuencia de los cambios sociales. Cuestiones como la caracterización de sus congéneres "chetos" y las menciones a referentes literarios, filosóficos, políticos y musicales de rock y de jazz rock, definían un conjunto con competencias formativas y estilos de consumo cultivados que recortaba a los ojos lectores los perfiles juveniles que Humor atraía. La reflexión de uno de ellos sintetizó el interrogante identitario que había rondado el encuentro:

De una discusión que debió ser un juicio a los jóvenes, se pasó a una charla en la cual los jóvenes se expresan. Con las mismas contradicciones con las que vivimos. ¿Qué es lo que nos define como jóvenes? Nada nos es real y todo nos es posible. En alguna medida, lo sentimos así. Sentimos que podemos ser los reformadores, pero también sentimos que no podemos hacer nada. O que no nos dejan. (7)

$\mathrm{Ni}$ la identificación con los y las "jóvenes blancos" ni con la militante de sus mayores; ni desentendidos de su tiempo ni a la vanguardia de ningún acontecimiento colectivo, estos sujetos encontraban en Humor un espacio de expresión donde aparentemente podían plantear sus "contradicciones" y articularlas en torno a algunos fenómenos que los y las reunían, según veremos en el apartado siguiente. 
Ediciones de la Urraca, responsable de Humor, venía por otra parte contemplando el mercado juvenil con productos específicos como la revista Rock Superstar, primero, más tarde con la similar Hurra y con la revista-libro de ciencia ficción, El Péndulo (ver Burkart, 2017). Pero la visibilización de este segmento social en Humor expandía cualquier imagen preconcebida de su público y, por ende, de su contrato de lectura. (8)

La predisposición mostrada por la revista se prolongó en la incorporación de colaboradores jóvenes. De hecho, en la mesa redonda intervinieron tres futuros integrantes del staff de Humor: Miguel Repiso, de 18 años, humorista gráfico; Eduardo Mileo, de 25 años, con el tiempo responsable de la coordinación general y gráfica de Humor, y Gloria Guerrero, de 21 años. Nos detendremos en la producción de esta última, por cuanto sus artículos y la sección a su cargo llegaron a cobrar trascendencia y permitirán observar otras representaciones sobre sujetos juveniles en la revista.

\section{Gloria Guerrero: jóvenes, rock y periodismo en Humor.}

Guerrero estuvo vinculada al circuito de publicaciones juveniles "subte" de mediados de los años 70 y más tarde colabora en la revista Expreso Imaginario, en temas relacionados con la música rock. En ella hizo sus primeras armas en la práctica profesional, hasta responsabilizarse de la dirección de Hurra, -sucesora de otra también a su cargo, Rock Superstar-, donde mantiene su orientación periodística musical, mientras comienza a publicar en Humor (Guerrero, 1995).

Su nota inicial, donde es introducida como exponente juvenil, (9) retomaba algunos tópicos enunciados en el encuentro gestado por Dolina. Se focalizó en la categorización contrapuesta de "chetos" y "rockeros", ironizando sobre las 
prácticas que atribuía a quienes, por su incapacidad de alcanzar los consumos de los primeros, adoptaban los modos de los y las segundos. Frente a lo que calificaba como una moda rockera, Guerrero le contraponía la pertenencia auténtica al movimiento, con el que se identificaba.(10) Daba cuenta, así, del consabido antagonismo del movimiento frente al mercado y de las suspicacias frente a posibles recuperaciones de las señas de diferenciación juvenil en clave de consumos estandarizados (ver Alabarces, 1993). Su autoridad argumentativa, entretanto, descansaba en la legitimación introductoria de la revista y, sobre todo, en su propia experiencia como crítica en el recorrido de las "subte" a la prensa profesional. Por otra parte, en el debate epistolar en la revista ya descrito había sido problematizada la cuestión de la "autenticidad" de su público, contraparte necesaria del fenómeno discográfico y espectacular del género.(11)

Así, lectores y columnista de Humor coincidían en la intención de establecer la identidad rockera, diferenciada por contigüidad de la figura "cheta" y de quienes eran vistos como advenedizos en el movimiento. Estos posicionamientos recapitulaban la estratificación fáctica en los consumos juveniles y la relación controvertida entre las pretensiones artísticas en torno al rock, su público y el mercado.

Si Guerrero la había emprendido contra la "pose" rockera inauténtica, en su siguiente nota tematizó el fenómeno disco, núcleo del consumo musical de los y las "chetos", focalizando en su animador, el musicalizador o disc-jockey. Su juicio sobre este actor, de acuerdo a lo anticipado en el título ("Estrellas de la anticultura") y al testimonio de uno de ellos citado para fundar su texto, resultaría fulminante: 
Artífice de la gran pavada universal de mezclar ritmos extravagantes con sudores de cuerpos argentinos, alimentador del frenesí banal y estúpido de moverse porque sí, aislando el cerebro y el alma del resto del organismo, y anulándolos irreparablemente, y -por sobre todas las cosasculpable de llevar las narices del mundo joven hacia los rincones más pestilentes de la mediocridad. Demasiado lejos de donde (todavía) esperan y trabajan los pocos artistas lúcidos que no se han desmoralizado del todo. (12)

En consonancia, el artículo replicaba la clasificación social respecto a los géneros musicales, donde el criterio de autenticidad residía en la música "no comercial", mientras que la disco quedaba del lado del mercantilismo y la mediocridad -ideologema reiterado de un medio que llegó a ostentar como eslogan "la revista que supera, apenas, la mediocridad general" (Burkart, 2017; Raíces, 2019)- y, finalmente, la "anticultura".

Manteniendo el juego de oposiciones, Guerrero contrastaba una experiencia distinta, a la que atribuía el carácter de proveer un disfrute consciente. Era la obtenida en vivo, particularmente en los recitales de rock.(13) Mientras el baile suponía una situación controlada, el recital "con su significación performativa, su puesta en escena y su invocación desde un escenario [...], podía forjar alguna especie de liderazgo cultural. Potencialmente, era más peligroso un recital que el baile" (Pujol, 2007a, p. 92; también Alabarces, 1993, pp. 52-53). A partir de marzo de 1981, Guerrero obtuvo con "Las páginas de Gloria" una sección específica, definida por la revista como "un rincón para comunicarles pálidas y entusiasmos a sus coetáneos" (ver Burkart, 2012, p. 194). Humor 
inauguraba, así, un espacio específico y permanente de contenidos para los y las jóvenes y los reconocía formalmente como parte de su lectorado. Adicionalmente, ponía a una mujer a coordinarlo y a producir regularmente casi la totalidad de sus contenidos informativos y críticos dentro de un medio con predominante presencia masculina, condición solo compartida con la responsable de la sección de reportajes, Mona Moncalvillo.(14) Su juventud también la resaltaba en el contexto de una redacción adulta, en el que resaltaba su experiencia profesional, concentrada en pocos años. Es posible entonces deducir del curso de la trayectoria de esta mujer, joven, rockera y periodista hecha en el oficio -la "primera mujer periodista de rock de la Argentina", según la presentación del libro que compiló sus reportajes y notas (Guerrero, 1995)- el tono impreso a su discurso, en primera persona, provisto de aseveraciones y elecciones tajantes.(15)

La sección se compuso de modo variable con un apartado de noticias de grabaciones, lanzamientos, comentario de ediciones "subte", reseñas de recitales, crónicas de giras y reportajes; algunos apartados, como el de las crónicas de recitales, recordaban trabajos anteriores de Guerrero como los que llevó adelante en el suplemento "Mordisco" de Expreso Imaginario y en Hurra (Benedetti y Graziano, 2007, p. 64). En el apartado "Los rayados de Humor" se concentraron las críticas de discos, donde Guerrero se reservó las de las novedades relacionadas con el rock.

"Las páginas de Gloria" se convirtió en un espacio de difusión de grupos y solistas relacionados con el rock en el espectro relativamente amplio del pop, el jazz-rock, el folk y la canción de autor. Tal como había sucedido desde sus notas iniciales, la selección ofrecida fue marcando sus preferencias y rechazos y evidenciaba la intención crítica (Bourdieu, 1967, p. 153) tendiente a generar 
canon, clasificando y evaluando artistas y producciones (y también a sus públicos), con sus inclusiones y exclusiones. Así, por ejemplo, valoró las incursiones rockeros y rockeras en otros géneros como el folklore o el jazz como fusión (ver Alabarces, 1993, pp. 32-33 y 55-59), bendecidas por un público juvenil numeroso en los distintos festivales, por caso el "Encuentro de Música Popular" organizado por la revista y desarrollado en agosto de 1981 (Raíces, 2019, pp. 168-174). A la inversa, desestimó el punk rock, al considerarlo un estilo minoritario, estridente, réplica de modas metropolitanas y promotor de disturbios en sus recitales, que desacreditaban a un movimiento musical cuyos espacios públicos habían mermado en los años anteriores. En este aspecto, resultó constante su cuestionamiento a los comportamientos juveniles violentos del público espectador y su advertencia a los y las músicos sobre su responsabilidad en promoverlos o desalentarlos (ver Alabarces, 1993 y Pujol, 2007b). (16).

Al mismo tiempo, "Los rayados de Humor" (17) funcionó como registro de las novedades discográficas y supuso, por otra parte, un punto de contacto de la revista con la industria. Esta comenzó a enviar las novedades discográficas, a insertar publicidad de lanzamientos y recitales y consolidó de hecho la sección, al propiciar una nueva fuente de ingresos directos para Humor, directamente relacionada con su público juvenil -y que probablemente impulsó pauta destacada de otros productos que les eran relacionados, como los jeans sobre los que ironizaba Dolina-. (18)

En "Las páginas..." también encontró conciso espacio otra iniciativa juvenil, la de las revistas "subte", en la que como se mencionó Guerrero había tomado parte con anterioridad a 1976. Estos medios autogestionados condensaron durante la dictadura relevantes registros de la producción cultural juvenil en los 
términos contraculturales mencionados (Margiolakis, 2016). Guerrero les dio difusión regular acusando recibo de los envíos de ejemplares y efectuando breves valoraciones de cada publicación. Continuaba así una labor de difusión iniciada en Expreso Imaginario (Benedetti y Graciano, 2007, pp. 84-86), pero potenciada ahora por la llegada nacional superior de Humor. Sus evaluaciones, a partir de su antigua pertenencia a un campo editorial que consideraba haber contribuido a establecer, no eran menos categorías que respecto a sus preferencias musicales. Como evidencia confirmatoria de su rol referencial, en la sección la crítica destacó las dificultades que le generó la multiplicación de envíos de publicaciones. (19)

Las circunstancias alrededor del conflicto de Malvinas promovieron una acelerada expansión del género en los medios, multiplicaron las ediciones discográficas y facilitaron el acceso a escenarios cada vez más masivos. Al tiempo que, merced a su consolidación comercial, se asentó su etiquetamiento como "rock nacional" en desmedro de su originaria identificación contracultural (Alabarces, 1993, pp. 84-86; Pujol, 2007, pp. 218-233; Benedetti y Graziano, 2007, pp. 164-166). No obstante, para Guerrero ese presente expansivo podía permitir consolidar definitivamente sus credenciales artísticas:

Durante más de diez años se ha luchado por imponer un estilo de música que representa a un nutrido sector de la juventud argentina. Burlas, represión, rechazo, denuncias y escándalos mediante, el rock nacional no pretendía laureles honoríficos sino tan solo un respetable y digno lugar dentro de la cultura del país. [...]. ¿Y? ¿Qué hay para mostrar? (20) 
En este juicio incidía la autopercepción de su rol intelectual en tal sentido, que la autorizaba a la hora de proclamar el reconocimiento y exigir "calidad" subsiguiente en términos de la jerarquización profesional y artística de los y las intérpretes y compositores, entre otros aspectos enumerados en su artículo. Otra de sus propuestas para afianzar el movimiento volvía sobre el imperativo del correcto comportamiento del público espectador, completando el circuito de los actores constituyentes de la identidad rockera. Por fuera de él quedaban la industria cultural y los y las adultos, que venían finalmente a aceptar ese "respetable y digno lugar" reclamado por la música joven.

Puede decirse que la sección constituyó globalmente una apuesta a argumentar sobre la legitimidad cultural del rock. Su titular sostuvo un discurso crítico no solo aplicado a la actualidad musical sino que a través de ella pero también de pronunciamientos específicos se posicionó de modo reflexivo sobre la inserción del rock en la sociedad como expresión distintivamente juvenil.

\section{Jóvenes y política, del rock al voto.}

La derrota en el conflicto por las islas Malvinas tuvo como consecuencia inmediata la descomposición acelerada del régimen y abrió una etapa de movilización social y política, en términos de ocupación del espacio público, reactivación partidaria e incremento de las afiliaciones -dado que la actividad de los partidos estaba suspendida desde el golpe de estado-, bajo la expectativa del llamado a elecciones para el retorno al orden constitucional (Aboy Carlés, 2001, p. 167; Pujol, 2005a, pp. 252-254; Colombo, 1985). Este escenario potenció la liberalización discursiva en la prensa y radicalizó las posturas críticas en Humor, de la mano de sus columnistas políticos (Burkart, 2017, p. 263 y ss.). 
En ese marco, la juventud fue nuevamente tematizada en la revista con relación al futuro democrático. Para 1983 se calcularía la existencia de 6 millones de jóvenes con edades entre 18 y 25 años (Pujol, 2005a, p. 252), que nunca habían ejercido el voto pero tendrían gravitación notoria en los resultados de los comicios. Una nota de Gloria Guerrero aparecida en septiembre del año anterior, a poco de haberse anunciado la fecha eleccionaria, ofrecía su opinión asumiendo la voz de los y las jóvenes a solicitud de la revista. En su texto se reconocía ignorante en materia política a partir de describir su condición de crecida entre dictaduras y de reconocer su temor a partir de la ausencia de muchos congéneres, fallecidos por la represión, la guerra de Malvinas o haber partido al exilio. Evocando su incomprensión de las juventudes políticas de su etapa estudiantil previa a 1976 y de las actuales en retorno, Guerrero les contraponía fragmentos de letras de canciones de rock que exhibían crítica social e ideales de paz y justicia social, a modo de credo ideológico que abrevaba en la tradición contracultural (Pujol, 2007b). Si bien reconocía estar informándose y adherir al segundo término en la disyuntiva política entre la "bota" militar y el "voto" ciudadano -a través del juego de palabras-, reafirmaba de esta forma su identificación con los rituales colectivos del rock. (21) Su nota obtuvo contestación por dos cartas de lectores y un artículo de otro joven colaborador. Las misivas, firmadas por dos lectores de edad similar a Guerrero, le cuestionaban su indolencia y rechazo a interiorizarse sobre la realidad del país, a la vez que su "evasión" por la música. Ambas planteaban argumentos favorables al compromiso político, mientras que en la misma sección y a continuación Guerrero les replicaba reafirmando su desinterés en la política. (22) 
En el mismo número, un colaborador ocasional volvía sobre su texto con intención similar, desde la situación de mutuo conocimiento personal que el autor explicitaba. Con la particularidad adicional de que efectuaba la diferenciación entre el activismo de unas juventudes populares urgidas por la moratoria -jóvenes por edad, adultos y adultas por necesidad- y las vacilaciones de quienes podían ejercitar su juventud como tal por su condición de clase media -un "nosotros" autoral extensivo de Guerrero al lectorado de la revista-. (23) De todos modos, Fiebelkorn abogaba por la convergencia obrerojuvenil alentada por las expectativas, luego frustradas, de conformar un frentismo opositor (Colombo, 1985, p. 85), con un optimismo de época distante de miradas como la del chiste de Meiji.

Introducía su texto una ilustración de Fati (Luis Scafatti), bautizada "Argentina 76-82", que exponía a dos paseantes "chetos", vestidos con los usuales jardineros y absortos en la escucha musical, contra el trasfondo de la presencia de siluetas militares armadas. Unas tiras negras velaban sus ojos. Si bien estas estaban asociadas al empleo censorio para "adecentar" las publicaciones con desnudeces corporales, en este caso enfatizaban la renuencia de los personajes a observar una realidad ominosa. En tal sentido, la composición apuntaba a un contradestinatario compartido por Fiebelkorn y Guerrero, antes que a las diferencias que sustentaban la polémica. 


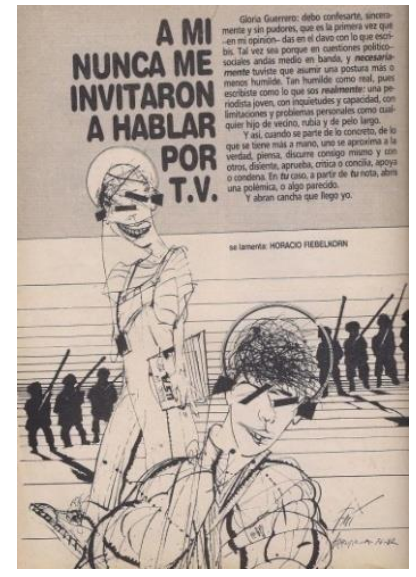

Obra de Fati en artículo de Fiebelkorn.

Humor, por otra parte, ya había publicado cautas reflexiones -de adultos- sobre juventud y política. En ellas, señalaron la confusión juvenil entre la militancia y la moda del "compromiso" en los primeros años 70 y reivindicaban la opción de quienes "no estuvieron en nada" pero persistieron en sus proyectos individuales (ver Raíces, 2019, pp. 305-307).(24) El escrito en tono confesional de Guerrero, por su parte, correspondía a las generaciones posteriores y pretendía mostrar la postura persistente de los y las que se sentían contenidos en un ámbito particular, el de la "cultura rock" argentina. Su antiautoritarismo, enfatizaba la columnista, la hacía compartir las expectativas sobre el fin de la dictadura y apreciar los valores democráticos, pero desde una praxis que se pretendía paralela y autónoma (Alabarces, 1993, p. 26; Pujol, 2005a, p. 168169 y 214). En otro lugar señalaba, al cuestionar la subespecie rockera punk: «Nos costó demasiado trabajo convencer a la opinión pública de que no somos peligrosos. [...] Estamos demasiado podridos de ponernos de acuerdo con la ley en que no rompemos nada, como para que vengan ustedes detrás a arruinar lo que logramos: hacer la nuestra con tranquilidad». (25) Pero, como 
sugería la réplica de Fiebelkorn -y las de lectores-, el escenario post Malvinas venía a diversificar esa identificación entre las juventudes.

En el número siguiente, la representación gráfica volvió desde el recurso del humor gráfico a proponer una posible síntesis al respecto. Una viñeta de Hermosilla Spaak destacaba el posible cambio de perspectiva, de las razzias policíacas correlativas en dictadura a los recitales, a la eclosión opositora.

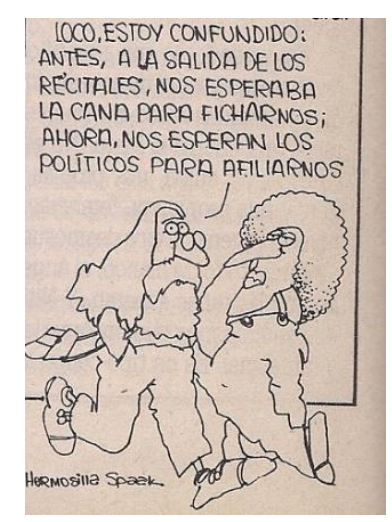

Viñeta de Hermosilla Spaak.(26)

Y otro colaborador adulto, el filósofo Santiago Kovadloff, publicaría dos artículos que indagaban los coloquialismos del lenguaje juvenil -clasemedieroy el destino de sus portadores en dictadura. Valoró en ellos su léxico e inflexiones como una resistencia a la opresión, en tanto que deploró la "disolución generacional" propinada por el "extremismo" guerrillero que había seducido a una parte de la juventud y por el equivalente "extremismo" militar. Para Kovadloff, la represión se había encarnizado con los y las jóvenes revolucionarios instrumentalizados y con la clase obrera (en la que no diferenciaba sectores juveniles, una vez más naturalizados). Culminaba propugnando que el futuro gobierno constitucional debía fomentar la "vida cívica" en la juventud y en los sectores populares frente al autoritarismo. Donde 
Fiebelkorn deslizaba la esperanza de una convergencia, el articulista veía la necesidad de interpelar a dos pilares sociales decisivos desde los valores democráticos liberales para afirmar el futuro orden constitucional. Una concepción que, por lo demás, enlazaría con los ejes de la campaña del candidato presidencial de la Unión Cívica Radical, Raúl Alfonsín (Aboy Carlés, 2001, pp. 171-172). (27)

\section{Conclusiones}

La pregunta/desafío planteada por Dolina para abrir su ensayo se producía cuando la juventud, de catalizador de las transformaciones sociales había pasado a personificar el caldo de cultivo "subversivo" a ser vigilado $y$, eventualmente, violentamente suprimido. Sus ácidas observaciones, referidas a los y las jóvenes inmersos en el nuevo clima cultural generado por la apertura económica, encontraron respuesta epistolar en aquellos y aquellas que leían Humor sin identificarse con ese modelo e indicaban que el público atraído por la revista también los y las concernía. Pero, sobre todo, dieron oportunidad a su inquietud de expresarse en condición de tales, como se desprendió de la instancia de diálogo en persona generada por Dolina, de acuerdo a su transcripción en Humor.

En la misma instancia de correspondencia y en algunos artículos comenzaban, en el mismo sentido, a reiterarse señas de identidad relacionadas con uno de los consumos y las prácticas tolerados en el contexto de clausura pública, el de la "cultura rock". Si bien Ediciones de la Urraca había apuntado con publicaciones específicas a este sector Humor, desde su perfil deudor del humor político y costumbrista comenzó a contemplar a esos y esas jóvenes a través de su presencia temática pero, fundamentalmente, a partir de su 
inserción en la revista como colaboradores. El "rock" supuso una referencia permanente de la juventud en sus páginas, a partir del momento en que una de ellas, Gloria Guerrero, inició la sección a su cargo a principios de 1981. Ello mientras la revista comenzaba a "politizarse", a escalar la sátira y la discursividad "seria" contra la dictadura y a experimentar la etapa más exitosa de su prolongada existencia.

"Las páginas de Gloria" propulsaron su propia "política" mediante la labor de difusión, crónica y crítica y propuso un canon de calidad y de respetabilidad de las producciones y de las prácticas relacionadas con la "música joven". Un discurso de distinción, con contradestinatarios acordes a la suspicacia del movimiento rockero argentino respecto al mercado, fueran la "música disco" y sus estilos de consumo asociados o eventuales modas rockeras, frente a los cuales reivindicaba una "autenticidad" fundada en la herencia contracultural originaria. Los y las jóvenes rockeros, según Guerrero -tan poco satírica al definir posiciones como los y las columnistas "serios" de la revista-, detentaban voz propia y derecho a poder afirmarse públicamente como tales sin represiones. Pero esto también dependería de su comportamiento responsable y consciente de los límites, de la "madurez" que demandaba a los distintos actores del movimiento en el ocaso dictatorial, cuando el género parecía consagrarse en la escena pública mediática y mercantil.

Vistas las disparidades etarias entre rockeros y rockeras cuyas participaciones en la revista hemos relevado, su condición de congéneres a partir del rock debiera pensarse sostenida en una "alianza del gusto" que los y las unía en el movimiento más allá de las eventuales diferencias de intereses entre subgéneros, fusiones y "tribus" (Pujol, 2007a, p. 253). 
En las postrimerías del régimen, las expectativas sociales generadas por el paso a un nuevo gobierno constitucional, suscitaron algunas colaboraciones "serias" de reflexión sobre la incidencia de unas juventudes en edad electoral que habían crecido sin experimentar el funcionamiento de la alternancia democrática. Tanto el filósofo Santiago Kovadloff como otro joven colaborador, Horacio Fiebelkorn, conjugaron maneras de interpelación "de la época" que polemizaron abiertamente -en el caso del segundo- o de facto con profesiones de fe apolíticas como las declaradas por Guerrero en la senda desconfiada del alternativismo rockero. Si Kovadloff ponderaba la educación en los valores democráticos de una juventud víctima de los "extremismos" y resistente a la opresión como requisito de la estabilidad democrática, Fiebelkorn retomaba la añeja perspectiva del compromiso, al llamar a los y las jóvenes a insertarse activamente en las luchas de su presente, en línea con la movilización contemporánea.

El humor gráfico y la ilustración, en tanto, tuvieron su parte en la construcción de estereotipos juveniles en la revista, en complemento de las elaboraciones escritas. Tanto los chistes de Meiji y Hermosilla Spaak como el trabajo de ilustración de Fati supusieron escenas que estereotipaban para el efecto cómico o reflexivo buena parte de los elementos componentes de sus actitudes y prácticas en dictadura. Los signos de distinción de clase, la denuncia satírica de las actitudes consumistas-conformistas y, finalmente, el dilema de quienes admitían, como Guerrero, incerteza ante el desafío de tener que ejercer su condición cívica por primera vez.

Para concluir, la revista Humor contribuyó desde sus distintos lenguajes a lo largo de los años dictatoriales a presentar una figura juvenil próxima a sus valores y contrato de lectura, centrada en las clases medias urbanas desde la 
lectura socioeconómica. Y caracterizada por su inconformismo, un interés participativo no necesariamente vinculado con la vía política y por su identificación sustancial con la música rock como significante organizador.

\section{Notas}

(1) Guerrero, G. (Diciembre de 1982). Tres sábados más de B.A. Rock. Y el sol se puso, nomás. Humor n 95 , pp. p.98-99.

(2) De la nómina de los y las detenidos desaparecidos volcada en la edición consultada del Nunca Más, casi el $80 \%$ se encontraba incluida en el rango de los 16 a 35 años. En la franja que va de los 21 a los 30 años, la estadística supera el $58 \%$ del total.

(3) Dolina, A. (Febrero de 1979). La amenaza del jean. Humor n 9, pp. 31-33.

(4) Ver, por ejemplo, Humor $n^{\circ} 24$ (Diciembre de 1979), portada crítica de la importación con la primera aparición del líder de facto, general Videla; n 46 (Noviembre de 1980), portada satiriza la quiebra de la industria nacional (editorial en p, 19 de apoyo a la industria editorial local, declaraciones en pp. 19 y $45-46)$.

(5) Humor no 9 (Enero de 1979), p. 40. "Meiji” es el seudónimo de Jorge Hipólito Meijide.

(6) Comienza en el número 7, de diciembre de 1978 y se prolonga hasta el número 11, cuando la revista anuncia la suspensión de la polémica.

(7) Luis Michi, 25 años, en Dolina puso la cara y pregunta: ¿a quién le ganaron los jóvenes? (Abril de 1980) p. 73. Humor $n^{\circ} 11$, pp. 68-73. El texto es acompañado de fotos de los participantes, cuya visión permite al lector comprobar la concurrencia y signos indumentarios que sugieren la homogénea extracción social del grupo juvenil presente. 
(8) Cascioli la definía en 1980 como «apta para toda la familia» (en el sentido de su consumo por todo el grupo familiar) y estimaba que su lectorado en la franja de 18 a 25 años, componía el $40 \%$ del total. Declaraciones en ¿Y, publicitarios, nosotros cuándo entramos en pauta? (Septiembre-octubre de 1980). Intermedios, año 8, n 10, pp. 20-21. Dos años después, la revista califica a su público mayoritario de «joven y pensante». Las bases de 'HUMOR”. (Noviembre de 1982). Humor n 94, p. 5.

(9) «...Opina sobre sus coetáneos, sin que nadie le indique lo que debe decir». Guerrero, G. (Marzo de 1979). Ahora hay que ser rockero, p. 44. Humor $n^{\circ}$ 10, pp. 44-45 (copete introductorio de la revista).

(10) lbídem.

(11) Por ejemplo, carta de Darío A. Fariña, p. 12. (Abril de 1979) Humor $n^{\circ}$ 11, pp. 12-13.

(12) Guerrero, G. (Abril de 1979). La fiebre de los disc-jockey. Estrellas de la anticultura, p. 32. Humor, no 11, pp. 32-35.

(13) Comentando un recital de León Gieco, Guerrero afirma: «La juventud argentina de rock no compra espejitos de colores. Si se nos encienden las caras y se nos larga la risa, será porque lo que nos mueve es válido. Porque nos pertenece. Porque no nos miente». Ídem. (Mayo de 1981). ¿Y vos qué curtís? ¿La Biela o el estadio Obras?”, p. 92. Humor n 58, pp. 9293. Aquí se advierte su modo discursivo de ligar "autenticidad", "verdad" e identidad colectiva en el acto en vivo del recital.

(14) A mediados de 1983 ( $n^{\circ} 106$, junio de 1983), Guerrero y Moncalvillo eran las únicas integrantes del "Cuerpo Especial de Dibujantes y Redactores". Incluso entre las colaboraciones son contadas las mujeres con responsabilidad de pluma (la articulista María Elena Togno y la dibujante 
francesa Claire Brétécher). Mayor presencia existe en las tareas de asistencia, corrección, laboratorio, publicidad y recepción.

(15) Guerrero cubrió las apariciones de intérpretes rockeras como Claudia Puyó, sin dejar de remarcar que el rechazo a un grupo femenino como las Bay Biscuits, patrocinado por los consagrados Seru Giran se debía, entre otras razones, al "aún poderoso machismo porteño". (Enero de 1982). Humor $n^{\circ} 74$, p. 97.

(16) Guerrero, G. (Mayo de 1979). Odien a estos bichos: a ellos les gusta. Humor $\mathrm{n}^{\circ}$ 14, pp. 38-41; ídem. (Agosto de 1981). Punks go home. Humor $\mathrm{n}^{\circ}$ 64, pp. 92-3. Además, juzgaba al género extraño a Latinoamérica. "Metalero/a" denomina a los y las seguidores del género heavy metal. Durante 1982 y 1983 se registraron varios incidentes violentos en recitales y festivales y la cuestión ocupa un reportaje al grupo de heavy metal Riff, con seguidores asociados a conductas violentas. Ídem (Abril de 1983). Riff y los cuernos de la discordia. 'Pronto nos van a culpar de terrorismo...'. Humor n' 103, abril de 1983, pp. 96-98.

(17) Este apartado inició en (Marzo de 1981). Humor n 54, pp. 94-95.

(18) Véase, por ejemplo, la campaña de jeans Wado's, entre fines de 1982 y principios de 1983 durante varios números de la revista, seguida por otra similar de Maverick Jeans and Jackets y, también, algunos avisos sueltos de la marca de ropa deportiva Dipporto. Cf. contraportadas Humor, $\mathrm{n}^{\circ} 90$ a 97 (Septiembre de 1982 a enero de 1983), no 111 (Agosto de 1983) y 106 (Junio de 1983), respectivamente.

(19) A poco de comenzar la sección, señalaba que «los editores de revistas subterráneas (...) se enfurecen si no comento sus publicaciones con la celeridad que ellos suponen sería la correcta. A este escritorio llegan 
alrededor de veinticinco ejemplares por mes, y es absolutamente imposible dedicarles todo el espacio que pretenden». (Junio de 1981). Humor, $n^{\circ} 61$, p. 89.

(20) Guerrero, G. (Julio de 1982). Si al rock le llegó su hora, que no le pase el cuarto, p. 97. Humor $n^{\circ} 85$, pp. 97-99.

(21) Guerrero, G. (Septiembre de 1982). Jóvenes y Urnas. De política, sólo sé que no sé nada. Humor, n 90 , pp. 42-43.

(22) Cartas de María T. Garcea y Jorge R. Alonso y respuesta de Gloria Guerrero. (Octubre de 1982). Humor, n 92, pp. 22-23.

(23) Fiebelkorn, H. A mí nunca me invitaron a hablar por T.V. ibídem, pp. 9293.

(24) Arias, A. (Agosto de 1980). La generación nostálgica. Humor, n 40, pp. 47-9.

(25) Guerrero, G. (Mayo de 1979). Odien a estos bichos: a ellos les gusta. Humor $n^{\circ} 14$, pp. 38-41.

(26) (Octubre de 1982). Humor $n^{\circ} 93$, p. 100. Hermosilla Spaak contaba a la fecha de la publicación con 29 años. Meiji y Fati coincidían en una edad de 35 años.

(27) Kovadloff, S. (Noviembre de 1982). ¡Loco, qué pálida el lenguaje juvenil! Humor n 94, pp. 18-19; ídem, (Abril de 1983). Juventud, el tesoro inmolado. Humor n 103, pp. 40-41.

\section{Referencias bibliográficas}

Aboy Carlés, G. (2001). Las dos fronteras de la democracia argentina. Rosario: Homo Sapiens. 
Alabarces, P. (1993). Entre Gatos y Violadores. El rock nacional en la cultura argentina. Ciudad Autónoma de Buenos Aires: Colihue.

Benedetti, S. y Graziano, M. (2007). Estación imposible. Ciudad Autónoma de Buenos Aires: Marcelo Héctor Olivieri editor.

Bourdieu, P. (1967). Campo intelectual y proyecto creador, en AA.VV., Problemas del estructuralismo (pp. 135-182). México: Siglo XXI,

Burkart, M. (2012). HUM®: La risa como espacio crítico bajo la dictadura militar. 1978-1983 (Tesis de doctorado). Ciudad Autónoma de Buenos Aires, Biblioteca Prof. Norberto Rodríguez Bustamante, Facultad de Ciencias Sociales, Universidad de Buenos Aires.

Burkart, M. (2017). De Satiricón a HUM®. Risa, cultura y política en los años setenta. Ciudad Autónoma de Buenos Aires: Miño y Dávila.

Colombo, A. (1985), Movilización y pluralismo en la Argentina. En Colombo, A.

y Palermo, V., Participación política y pluralismo en la Argentina contemporánea (pp. 7-96). Ciudad Autónoma de Buenos Aires: CEAL.

CONADEP (1995 [1985]). Nunca más. Ciudad Autónoma de Buenos Aires: EUDEBA/La Página.

Guerrero, G. (1995). La historia del palo. Diario del rock argentino 1981-1994, Ciudad Autónoma de Buenos Aires: De la Urraca.

Manzano, V. (2010). Juventud y modernización sociocultural en la Argentina de los sesenta. Desarrollo Económico, 199, octubre-diciembre, 363-389.

Margiolakis, E. (2016). La conformación de una trama de revistas culturales subterráneas en la última dictadura cívico-militar argentina y sus transformaciones en postdictadura (Tesis de doctorado). Ciudad Autónoma de Buenos Aires, Biblioteca Prof. Norberto Rodríguez 
Bustamante, Facultad de Ciencias Sociales, Universidad de Buenos Aires.

Margulis, M. y Urresti, M. (1996). La juventud es más que una palabra. En Margulis, M. (editor), La juventud es más que una palabra (pp. 13-31). Buenos Aires: Biblos.

Pujol, S. (2007a). Rock y dictadura. Crónica de una generación (1976-1983). Ciudad Autónoma de Buenos Aires: Booket.

Pujol, S. (2007b). Rebeldes y modernos. Una cultura de los jóvenes, en James, D. (director). Nueva Historia Argentina. Violencia, proscripción y autoritarismo, 1955-1976 (pp. 281-328). Ciudad Autónoma de Buenos Aires: Sudamericana.

Raíces, E. (2019). Cultura, medios y política. Humor, Medios \& Comunicación, Línea y la disidencia cultural durante la crisis de la dictadura: 1978-1982 (Tesis de doctorado). Ciudad Autónoma de Buenos Aires, Biblioteca Prof. Norberto Rodríguez Bustamante, Facultad de Ciencias Sociales, Universidad de Buenos Aires. 